\title{
Ds Nüünitram
}

\section{Rolf H. Adler}

Prof. em. Dr. med., ehem. Chefarzt Innere Medizin, C.-L.-Lory-Haus, Inselspital Bern
Kürzlich wartete ich an der Haltestelle Wander aufs Nüünitram. Es ist schweizweit durch Mani Matter bekannt geworden: «Geschter z Nacht het ds Nüünitram statt hei i ds Depot z gah plötzlech niemer weis warum sys Schinegleis verla ...». Ich war auf einen Tramzug in Berner Farbe, also rot eingestellt. Zu meiner Überraschung rollte ein lindgrüner Wurm heran, und auf ihm in grossen, weissen Buchstaben geschrieben «MITEINANDER STARK», daneben einige Eishockeystöcke. Im Innern des Trams bei jedem Sitz auf dem Fensterbrett fand sich ein etwa 80 auf $20 \mathrm{~cm}$ grosser Kleber, darauf zwei Eishockeyhandschuhe, einer in den Farben des Schlittschuhclubs Bern, der andere lindgrün. Darunter ein Rätsel: «Welches SCB-Urgestein war schon zu einer medizinischen Untersuchung in der Lindenhofgruppe? Beat Gerber, der Mutz oder Bill Gilligan? Jetzt am Wettbewerb teilnehmen: www.miteinanderstark.ch.» Zweifach geködert fühle ich mich gezwungen, dem Rätsel nachzugehen, einmal, weil ich nicht ein Urgestein, aber doch einst ein Steinchen in der 1.Mannschaft des SCB war, und zweitens, weil hier ein fragwürdiges Spiel mit der Aufgabe der Ärzteschaft und eines Spitals getrieben wird. (Die Lösung des Rätsels darf nur «der Mutz» sein, sonst würde das Arztgeheimnis gebrochen.)

Die unverblümte Reklame mit der Verbindung der Stärke eines Spitals und seiner Ärzteschaft mit der - derzeitigen - Stärke des SCB bedarf der Diskussion! Prof. Hans Goldmann, Bern, war einer der grossen Augenärzte des 20. Jahrhunderts. Er wurde von Patienten aus der ganzen Welt aufgesucht. Sein Wissen, sein Können und seine ophthalmologischen Erfindungen sprachen ohne Reklame für ihn und seine Universitätsklinik. Er hatte es nicht nötig, seine Klinik als Schweizer Augenzentrum zu bezeichnen. Mein Onkel Georges Adler (1909-1995) war Arzt. Auf der $20 \times 10 \mathrm{~cm}$ messenden Messingtafel am Eingang zu seiner Praxis stand nur «Kinderarzt» - fertig. Er konnte von seiner Praxis leben und sich sogar ein Bild von Cuno Amiet erstehen. Hätte er mit zwei Kollegen im gleichen Haus gearbeitet, nie hätten die drei sich als Berner Pädiatriezentrum herausgestrichen.

Wie kann ein Arzt, eine Ärztin, ein Spital guten Gewissens behaupten, er, sie, es sei stark, ein Zentrum? Also eine Qualität für sich beanspruchen?

Der Begriff «Qualität» stammt aus der Industrie. Die Qualität eines Produkts kann umso schärfer erfasst werden, je weniger und einfache Parameter geprüft werden müs- sen, etwa die Messgenaugkeit eines Blutdruckgerätes oder eines zur Messung des Serum-Natriums. Bei der Betreuung von Patienten spielen verschiedenste Einflüsse mit, denn die Wissenschaft vom Menschen ist die Wissenschaft von der Natur des Menschen, und diese ist eine biopsychosoziale. So erfasst beispielsweise die DRG(= Diagnosis Related Group)-Einteilung den Patienten nicht, denn dieser ist kein Werkstück vom Fliessband. Dazu gibt es x Belege: z.B. erleiden Patienten nach einem Myokardinfarkt, wenn sie deprimiert und/oder sozial isoliert sind, häufiger Herz-Komplikationen als ausgeglichene, gut vernetzte Menschen. Ein banales Beispiel: «Ein Schnupfen hockt auf der Terrasse, auf dass er sich ein Opfer fasse. Er stürzt alsbald mit grossem Grimm auf einen Menschen Namens Schrimm. Paul Schrimm erwidert prompt "Pitschü!», und hat ihn dann bis Montag früh». Was aber Christian Morgenstern nicht gewusst hat: Paul steckt sich eher an, wenn seine Eltern sich nach der Scheidung nicht gemeinsam der Kinder angenommen haben als Peter Schramm, dessen Eltern sich zusammen auch nach der Scheidung um die Kinder kümmerten.

Also: Schnupfen ist nicht einfach Schnupfen, Pneumonie nicht einfach Pneumonie. Ob eine bald 80-jährige Frau, die ihren Mann mit 40 Jahren verloren hat und deren Kinder weit entfernt im Ausland leben, und die mit einer schweren Influenza B im Spital liegt mit einem CRP von 196 und dorsal basal feine, feuchte, nicht klingende, nicht weghustbare Rasselgeräusche aufweist, Antibiotika braucht oder nicht, kann nicht vom Nationalrat oder der Nationalrätin XY beurteilt werden als notwendige oder überflüssige Massnahme. Hier sind nur die hoffentlich gut ausgebildeten Ärzt(inn)en zuständig, und die Qualitätskontrolle kann nur durch noch erfahrenere Kolleg(inn)en beurteilt werden und wenn möglich in grossen, prospektiven Studien. Die Qualität wird nur von der Ausbildung der Medizinstudent(inn)en, der Assistenzärztinnen und -ärzte und der Ärzte und Ärztinnen in der Praxis, die Fortbildungen besuchen, garantiert werden.

Am leidenden Menschen darf niemand mehr verdienen, als seiner Betreuung des Kranken entspricht. Die Qualität kann nur von Ärztinnen und Ärzten beurteilt werden. Der Markt hat hier nichts, aber auch gar nichts verloren. Das grüne Tram gehört sofort ins Depot und auf rot umgefärbt. Mit diesem Artikel hoffe ich, der Prophezeiung von Wilhelm Busch entgegen zu treten, der sagte: «Vergebens predigt Salomo, die andern machens doch nicht so!» 